\title{
Eco-friendly Materials of Polymer Composites Based on Water Hyacinth Fibers/Roving
}

\author{
Nguyen Thuc Boi Huyen ${ }^{1}$, Nguyen Hoc Thang, ${ }^{1, *}$
}

${ }^{1} \mathrm{Ph} . \mathrm{D}$. Engineering, Department of Chemical Technology, Ho Chi Minh City University of Food Industry, Ho Chi Minh City, Viet Nam

\begin{abstract}
Overgrowth of water hyacinths will cause difficulties for water traffic in the Mekong Delta and affect the growth of other aquatic species. The water hyacinth as a raw material available in nature has been applied in production of the composite materials. The water hyacinth trees were treated in $\mathrm{NaOH}$ solution for 2-12 hours with concentration in the range 2.5-15.0\%. The morphology of the water hyacinth before and after treatment was characterized using scanning electron microscopy (SEM) which showed that the fiber surface structure as well as the arrangement order between the fibers was significantly changed. The green composites were fabricated on the background of an unsatured polyester resin that is reinforced with water hyacinth fiber. Mechanical properties of the composites were measured with a sharp increase in flexural strength and flexural modulus (nearly $300 \%$ increase) in the case of treated water hyacinth fiber composites / roving. Similarly, the compressive strength of composite materials increased significantly. This demonstrates the advantages of natural water hyacinths fiber treatment in relation to the mechanical improvement of the polymer composite materials.
\end{abstract}

Keywords: Eco-friendly materials, mechanical properties, morphology, polymer composites, treatment, water hyacinth

*Author for Correspondence E-mail: thangnh@ @ufi.edu.vn

\section{INTRODUCTION}

Water hyacinth is a wild plant, mostly found in lakes, ponds and rivers in Vietnam. It is particularly well-grown and thrives in the provinces of the Mekong Delta. Water hyacinth is an aquatic plant, characterized by a hollow structure of stem and leaf stalks, so all stems and leaves are floating on the water surface as

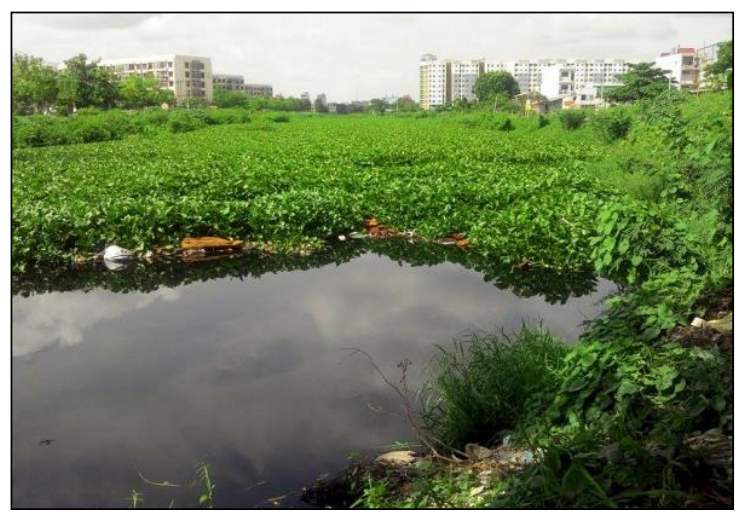

Fig. 1: Water Hyacinth Thrives in Canals at Binh Hung Hoa Ward, Tan Phu District, Ho Chi Minh City, Vietnam. shown in Figures 1 and 2. According to Apichote (2019), the hyacinth fiber surface structure is composed of hollow tubes, arranged in an orderly manner, where each single fiber is composed of several thousand tube units $[1,2]$. The overgrowth of water hyacinth will limit the growth of some other aquatic species; hence it is necessary to be

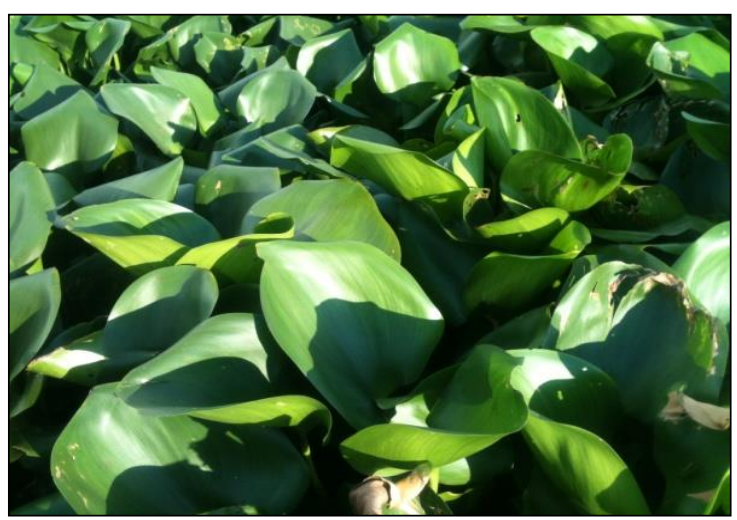

Fig. 2: Water Hyacinth Leaves Grow Dense on Canals and Rivers in Long An Province, Vietnam. 
taken to minimize the harmful effects of this plant. Some applications of water hyacinth in industries such as fine arts, fertilizer for crops, poultry feed, packaging or soil improvement.

Tumolva et al. was treated the water hyacinth with $\mathrm{NaOH}$ solution at the concentration less than $10 \%$ (in wt) for 24 hours [3]. At higher $\mathrm{NaOH}$ concentrations over $15 \%$, Ortenero et al. (2012) found that the water hyacinth fibers were susceptible to break [4].

Bali et al. (2015) reported that the extraction of some ingredients such as lignin, minerals, tree resin in water hyacinth will reveal the fibers on the body of the water hyacinth. Therefore, it is possible to observe the arrangement of the fibers of water hyacinth easily [5]. According to Kalia et al. (2009), treatment of the water hyacinth with $\mathrm{NaOH}$ solution will increase the surface roughness of the water hyacinth fiber compared with the untreated yarn. In addition, the treatment will cause some of the water hyacinth fibers to break, resulting in more spongy fibers due to loss of lignin and other substances [6]. According to Ramadevi et al. (2012), increasing the roughness on the surface of the water hyacinth fiber leads to increased bonding between the resin and the water hyacinth fiber in the composite [7].

The studies on sisal fibers reinforced composite material [8], strengthening on banana fibers [9, 10], and on coconut shell [11], jute fiber composites [12], the rice husk, corn cob polymer matrix composites [13] showed an increase in the mechanical properties of the composite. The composite-based materials are also reported to have good thermal insulation with high porosity and low thermal conductivity $[14,15]$.

In order to contribute to the effective use of water hyacinth, this paper studied the treatment of water hyacinth, a source of raw materials available in nature to produce environmentally friendly composites. This solution opened up a new way of application for the water hyacinths. And at the same time it contributes to reducing the harmful effects of water hyacinths on the water environment as well as creating ventilation for waterway traffic.

\section{MATERIALS AND METHODOLOGY}

Fresh water hyacinth raw material was collected in several canals and rivers in Long An province belonged to the Mekong Delta. Fresh water hyacinths were removed from green leaves, roots and stem parts that are yellowed or crushed. In this study, the welldeveloped water hyacinth plants were chosen with large stems and uniform in length and diameter.

\section{The Process of Preparation with the Water Hyacinth Fibers}

The water hyacinth was treated with dilute salt water and then washed several times with water. The water hyacinth was dried naturally at room temperature $\left(30^{\circ} \mathrm{C}\right.$ in Vietnam) for 24 hours. Nextly, the raw material was dried in an oven with circulating air until the weight of the water hyacinth remains constant. The dried water hyacinth was soaked with $\mathrm{NaOH}$ solution. After the treatment processes, the study was obtained the lignin extracts and the treated water hyacinth. The treated water hyacinth was continuously neutralized with acetic acid and washed several times with warm water to get a neutral value of $\mathrm{pH}$. Finally, the treated water hyacinth was dried to constant mass and prepared to be the reinforcement material for composite. The process of treating water hyacinth is shown in Figure 3.

The concentration of $\mathrm{NaOH}$ solution was changed from 2.5, 5.0, 7.5, 10.0 and $15.0 \%$ (in wt) to evaluate effects of sodium hydroxide to the water hyacinth properties. Moreover, the processes were carried out in different times at 2, 4,8 and 12 hours to consider the treated time to efficiency of the preparation. Morphology of water hyacinth and composite/water hyacinth was analysed by scanning electron microscope (SEM-JSM-6480LV) at Nanotechnology Institute-Ho Chi Minh City National University.

\section{Production of the Roving Reinforced Composite Materials Using Water Hyacinth Fibers}

The roving reinforcement composite materials were fabricated from two types of water hyacinth fibers: untreated and chemically treated. The strands of water hyacinth were arranged vertically and proceed to knit the 


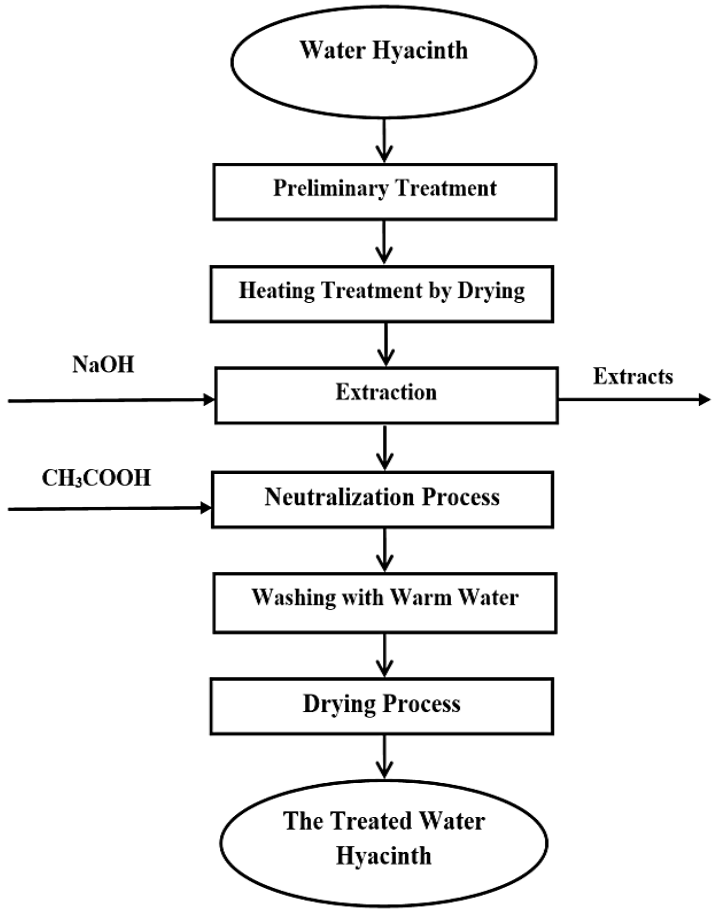

Fig. 3: The Preparation Process of Water Hyacinth Raw Material.

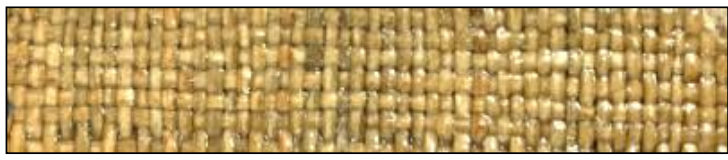

Fig. 4: The Roving Reinforcement Composite Materials using Water Hyacinth Fibers.

weft yarns in a one-yarn up-one-down structure. In turn, the weft fibers were knitted until formation of a roving plate. The unsaturated polyester resin (UPE) and curing agent was mixed and placed in a vacuum flask to separate air bubbles. The composite panels were formed in aluminum injection molds and they were removed out the mold after 3 hours. The plates of roving reinforcement composite materials were cured in an oven at a temperature of $150^{\circ} \mathrm{C}$ for 3 hours. Finally, the composite samples were cooled at room temperature for 24 hours to test for the mechanical properties. The surface of samples is shown in Figure 4.

\section{Evaluation on Mechanical Properties}

The mechanical properties of the composite samples were evaluated by the flexural and compressive strength and their modulus. The experiment was tested according to the standard of ASTM D790 using equipment of

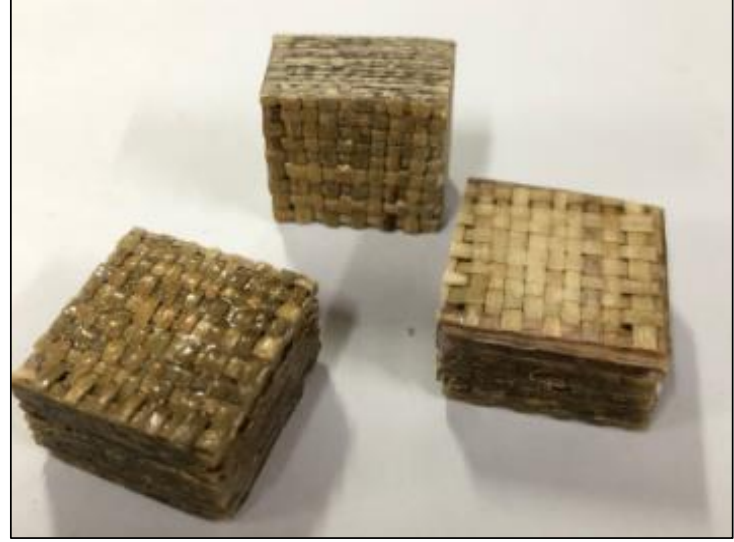

Fig. 5: The Roving Reinforcement Composite Materials using Water Hyacinth Fibers Prepared for the Compressive Strength Tests.

TESTOMETRIC at Polymer Laboratory, Ho Chi Minh City University of Technology and Education. In which, the testing process of flexural properties was conducted with moving speed of the clamp at $1 \mathrm{~mm} / \mathrm{min}$. The testing process of compressive strength was carried out with pressing speed of $1.3 \mathrm{~mm} / \mathrm{min}$. The samples for compressive strength tests were prepared in square section size of $20 \mathrm{~mm}$ and height at $12 \mathrm{~mm}$ as shown in Figure 5.

\section{RESULTS AND DISCUSSION}

Evaluation and Selection on the Treated Time and Concentration of $\mathrm{NaOH}$ Solution

Sodium hydroxide solution was used with concentration of $2.5,5.0,7.5,10.0$, and $15.0 \%$ (in wt) for the treated time at 2, 4, 8, and 12 hours. The results are shown in Table 1 and Figure 6.

Figure 6 shows that all of $\mathrm{NaOH}$ concentrations from $2.5-15.0 \%$ with the lignin content increased slowly during treatment time of 2-4 hours. In contrast, the treated time from 4-8 hours, the lignin content increased rapidly. In the time from 8-12 hours, the lignin content gradually decreased. The reduction of lignin in the extract related to the establishment of equilibrium lignin concentration in solution and in water hyacinth. Due to the higher lignin content in the extract than the lignin content in the water hyacinth which caused the reverse lignin shift from the outer extract into the hyacinth fibers. The results showed that at all $\mathrm{NaOH}$ concentrations between 2.5 and $15 \%$, the lignin content began to increase rapidly at 
Table 1: Effects of the Treated Time and Concentration of NaOH Solution to Lignin Content.

\begin{tabular}{|l|c|c|c|c|c|}
\hline \multirow{2}{*}{$\begin{array}{c}\text { Lignin content } \\
(\%, \text { in wt })\end{array}$} & \multicolumn{5}{|c|}{$\begin{array}{c}\text { Concentration of } \mathbf{N a O H} \text { solution } \\
(\%, \text { in wt) }\end{array}$} \\
\cline { 2 - 6 } & $\mathbf{2 . 5 0}$ & $\mathbf{5 . 0 0}$ & $\mathbf{7 . 5 0}$ & $\mathbf{1 0 . 0 0}$ & $\mathbf{1 5 . 0 0}$ \\
\hline 2 hours & 0.81 & 1.29 & 1.49 & 1.84 & 1.81 \\
\hline 4 hours & 1.29 & 1.45 & 2.04 & 2.52 & 2.54 \\
\hline 8 hours & 2.07 & 2.54 & 2.90 & 3.72 & 3.36 \\
\hline 12 hours & 1.93 & 2.76 & 3.49 & 3.08 & 2.95 \\
\hline
\end{tabular}

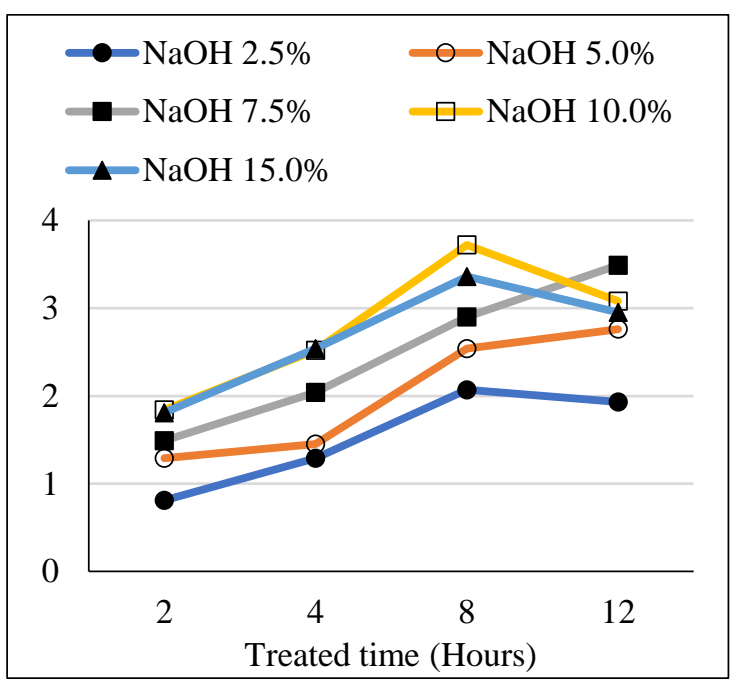

Fig. 6: Effects of the Treated Time and Concentration of $\mathrm{NaOH}$ Solution to Lignin Content.

a treatment time of 4 hours (Table 1 and Figure 6 ). Therefore, the time is suitable for treatment of lignin at 4 hours. The treated time for 8 hours was not chosen because lignin extract content was quite high. The loss of lignin content weakens the inner bonds of the hyacinth as well as the bonds between the fibers.

\section{Evaluation on Concentration of $\mathrm{NaOH}$ Solution}

In this experiment, the treated time was fixed at 4 hours. Concentrations of $\mathrm{NaOH}$ solution were changed at 2.5, 5.0, 7.5, 10.0, $15.0(\%$, in wt) with the lignin content as shown in Table 2.

With concentration of $\mathrm{NaOH}$ solution in the range of $2.5-7.0 \%$, the content of lignin has low value with only increases from 1.29 to $2.04 \%$. In contrast, the lignin content reached to the highest value in the range of the $\mathrm{NaOH}$ concentration from $10-15 \%$. However, in the range of high $\mathrm{NaOH}$ concentration (10-15\%),
Table 2: Effects of Concentration of $\mathrm{NaOH}$ Solution to the Lignin Content.

\begin{tabular}{|l|c|c|c|c|c|}
\hline \multirow{2}{*}{$\begin{array}{l}\text { Lignin content } \\
(\%, \text { in wt) }\end{array}$} & \multicolumn{5}{|c|}{$\begin{array}{c}\text { Concentration of NaOH solution } \\
(\%, \text { in } \mathbf{~})\end{array}$} \\
\cline { 2 - 6 } & $\mathbf{2 . 5 0}$ & $\mathbf{5 . 0 0}$ & $\mathbf{7 . 5 0}$ & $\mathbf{1 0 . 0 0}$ & $\mathbf{1 5 . 0 0}$ \\
\hline $\begin{array}{l}\text { Mass of lignin } \\
\left(\mathrm{g}, \mathrm{x} 10^{-3}\right)\end{array}$ & 1.90 & 2.90 & 3.90 & 5.80 & 4.80 \\
\hline $\begin{array}{l}\text { Lignin content } \\
(\%)\end{array}$ & 1.29 & 1.45 & 2.04 & 2.52 & 2.54 \\
\hline
\end{tabular}

the lignin content increased very little only; increased from 2.52 to $2.54 \%$. Therefore, the concentration of $\mathrm{NaOH}$ solution at $10 \%$ was chosen to carry out preparation of water hyacinth fibers for production of the green composite materials. It is noted that the $\mathrm{NaOH}$ concentration at $10 \%$ caused the lignin content begins to increase rapidly. The experimental results are consistent with previous research $[3,4,16]$. It should not conduct treatment the water hyacinth with high concentration of $15 \%$ $\mathrm{NaOH}$ because this causes waste of $\mathrm{NaOH}$ solution a lot that the lignin content does not change much. This is also consistent with the previous results of Ortenero et al. [4].

\section{Mechanical Properties of the Roving Reinforcement Composite Materials Using Water Hyacinth Fibers}

The composite materials were fabricated using UPE reinforced with roving plate made from water hyacinth fibers. In which, the roving plates were made from two types of water hyacinth included the treated water hyacinth (TWH) and the untreated water hyacinth (UWH) as shown in Figure 7.

The results of mechanical strength tests of the green composite materials are presented in Table 3.

Table 3: Mechanical Properties of the Roving Reinforcement Composite Materials using Water Hyacinth Fibers.

\begin{tabular}{|c|c|c|}
\hline \multirow{2}{*}{$\begin{array}{c}\text { Mechanical } \\
\text { Properties (MPa) }\end{array}$} & \multicolumn{2}{|c|}{$\begin{array}{c}\text { Type of the Green Composite } \\
\text { Materials }\end{array}$} \\
\cline { 2 - 3 } & UPE/UWH & UPE/TWH \\
\hline Flexural Strength & 11.05 & 31.11 \\
\hline Flexural Modulus & 344.16 & 1304.54 \\
\hline Compressive Strength & 246.42 & 408.16 \\
\hline Compressive Modulus & 281.35 & 526.81 \\
\hline
\end{tabular}




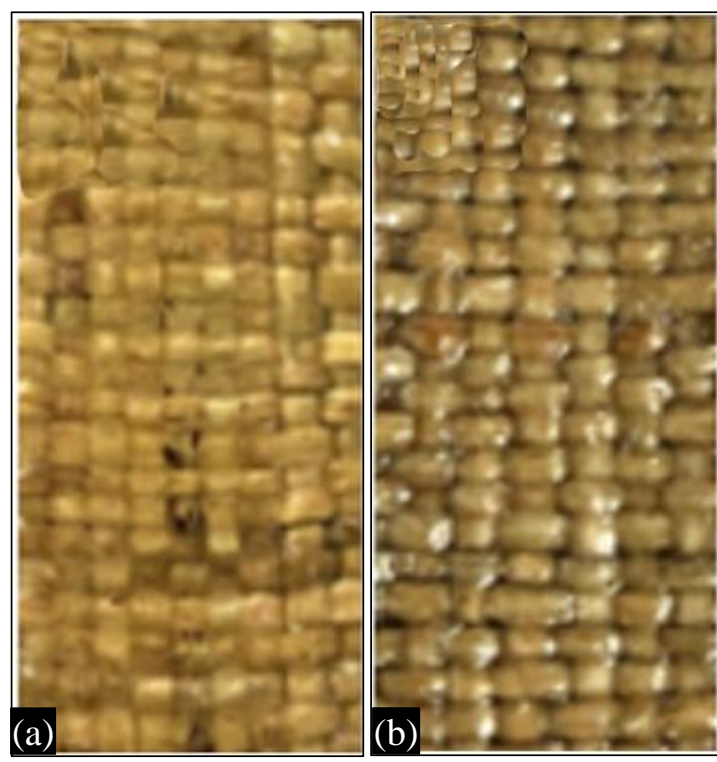

Fig. 7: The Roving Samples Fabricated from Water Hyacinth; (a) The Composite Sample with Untreated Water Hyacinth (UPE/UWH); (b) The Composite Sample with Treated Water hyacinth (UPE/TWH).

The experimental results show that the green composite materials based on the unsaturated polyester resin with untreated water hyacinth (UPE / UWH) has low flexural strength and flexural modulus of 11.05 and $344.16 \mathrm{MPa}$, respectively as shown in Table 3. However, for the green composite materials containing the treated hyacinth fibers (UPE / TWH), the values of flexural strength and flexural modulus are very high at 31.11 and 1304.54 $\mathrm{MPa}$, respectively. Thus, after the treatment of water hyacinth, the flexural strength of the composite increased by 3 times and the bending modulus increased by more than 4 times compared with the case of untreated water hyacinth (sample of UPE/UWH) as shown in Figure 8.

This suggests that the surface of the untreated water hyacinth fibers was covered with insoluble ingredients like lignin, pectin... which limits the compatibility of the water hyacinth with UPE resin, resulting in a low mechanical strength of the composites. After treatment, the water hyacinth fibers removed some of the coating components on the surface, increasing the area to contact among UPE background and fibers and lead to increase mechanical properties.

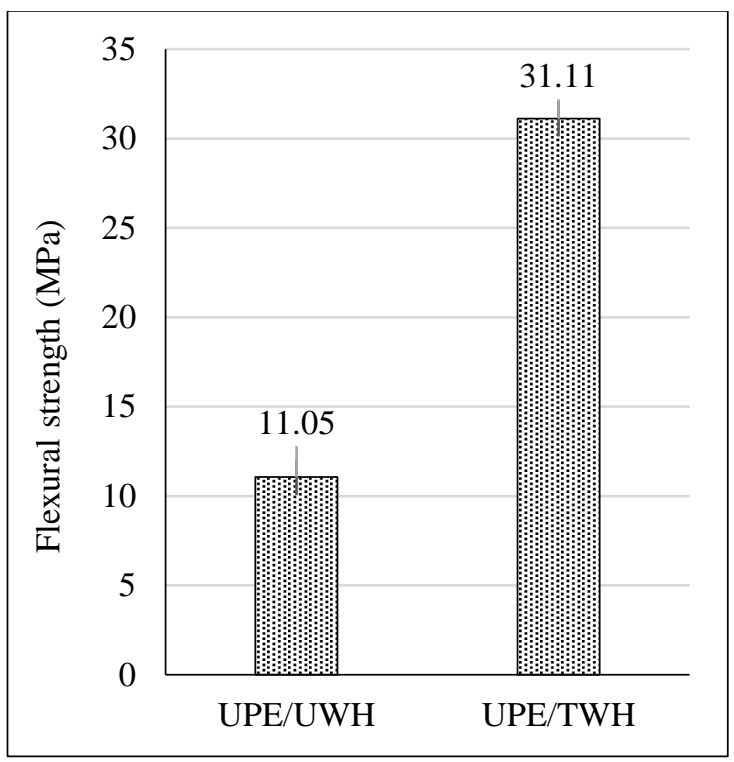

Fig. 8: Flexural Strength of the Roving Reinforcement Composite Materials using Water Hyacinth Fibers with Samples of $U P E / T W H$ and UPE/UWH.

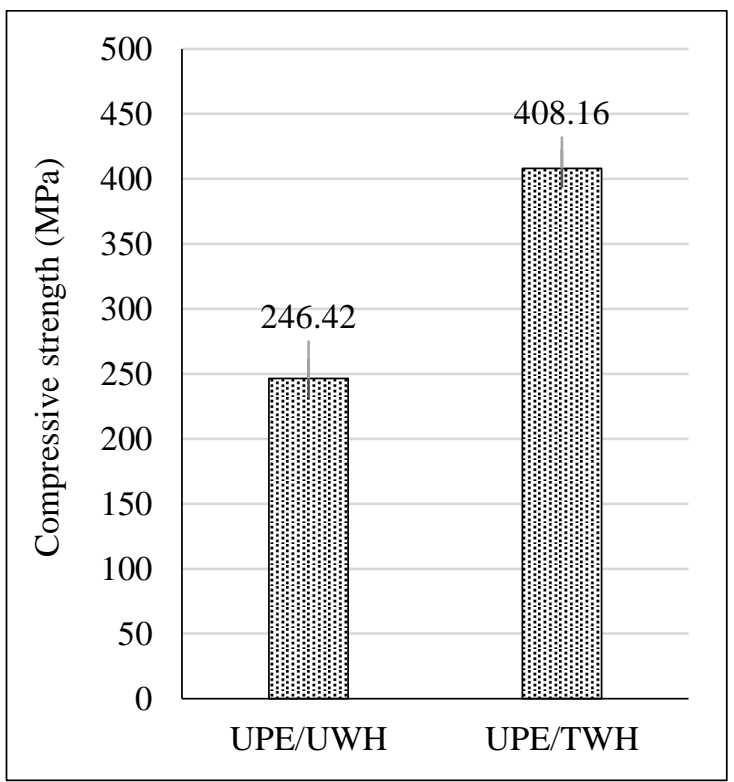

Fig. 9: Compressive Strength of the Roving Reinforcement Composite Materials using Water Hyacinth Fibers with Samples of UPE/TWH and UPE/UWH.

The compressive strength of treated water hyacinth composites is very high value at 408.16 MPa (Figure 9). The value is 1.66 times higher than that of untreated water hyacinth composite is at $246.42 \mathrm{MPa}$. Similarly, the compression modulus of treated water hyacinth composite is at $526.35 \mathrm{MPa}$ and it is 1.87 times higher than 
the composite materials without treated water hyacinth at $281.35 \mathrm{MPa}$.

Thus, the values of mechanical strength are consistent in significantly improving the properties of green composite materials reinforced with treated water hyacinth. The experimental results of the mechanical properties are consistent with the previous studies of composites on sisal fibers [8], on a banana thread $[9,10]$, and on a coconut shell [11].
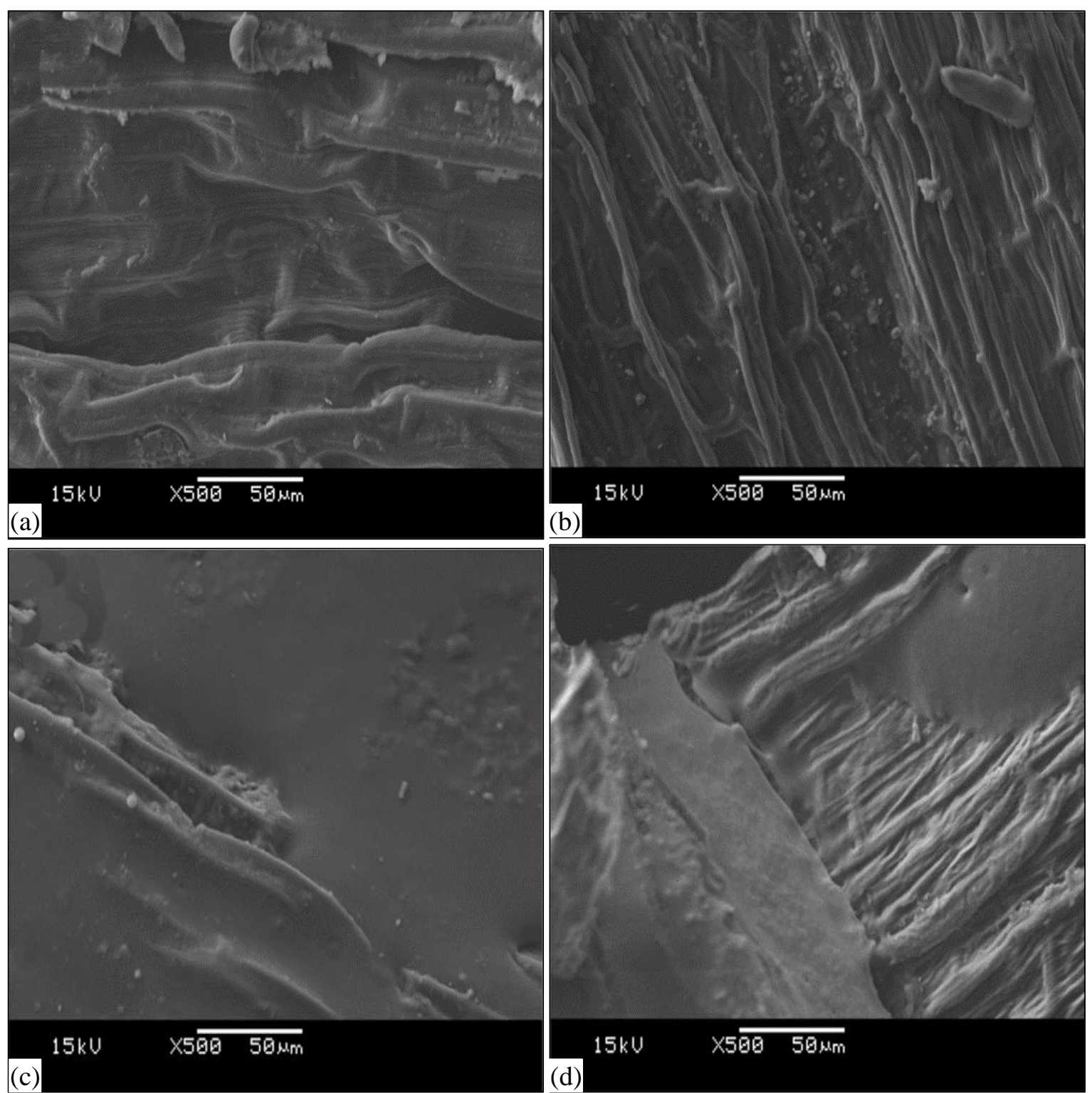

Fig. 10: Morphology of the Water Hyacinth Fibers and the Green Composite Materials, (a) Morphology of the Water Hyacinth Raw Material without Treatment (UWH); (b) Morphology of the

Water Hyacinth Raw Material Treated in NaOH Solution (TWH); (c) Morphology of the Geen Composite Material using the Untreated Water Hyacinth (UPE/UWH); (d) Morphology of the Geen Composite Material using the Treated Water Hyacinth (UPE/TWH).

\section{Microstructural Properties of the Water Hyacinth Fibers and the Green Composite Materials}

Morphology of the hyacinth before and after pre-treatment was observed using SEM. For the untreated water hyacinth fiber sample, it is difficult to observe the surface structure of the fibers on the SEM image (Figure 10(a)). In addition, it is also difficult to observe the arrangement between the water hyacinth fibers because some components such as lignin, pectin, hemicellulose and others 
solutes covered the entire fiber surface as well as the spaces between the fibers (Figure 10(a) and $10(\mathrm{c}))$. For the treated water hyacinth fibers, the sample was prepared with $10 \%$ $\mathrm{NaOH}$ solution for 30 minutes and at $40^{\circ} \mathrm{C}$ used to observe its morphology via SEM (Figure 10(b)).

fibers. Analytical results by SEM image on the treated water hyacinth fibers are consistent with the study of Bali et al. [5]. Figure 10(b) shows that the surface of the water hyacinth becomes rougher due to the loss of coating compound components on the fiber surface due to $\mathrm{NaOH}$ solution. Similarly to the SEM images of the water hyacinth composite material, Figure 10(d) shows the orderly arrangement of the water hyacinth fibers and there is a clear orientation between the fibers.

\section{CONCLUSION}

The research had the application of water hyacinth as a raw material for production of the green composite material. The products conducted the experiments on two types of the fibers: untreated water hyacinth and treated water hyacinth using $\mathrm{NaOH}$ solution. The experimental process determined the necessary concentration and treated time in the $\mathrm{NaOH}$ solution of the water hyacinth fibers so that the lignin extraction content has a high value but less $\mathrm{NaOH}$ consumption. The process extracted the lignin inside the fiber and among the water hyacinth fibers leading to a change in the chemical structure of the water hyacinth. The differences on morphology of the materials were observed by SEM with clearly orientation on structures the treated water hyacinth fibers. Mechanical properties such as flexural and compressive strength of the composite samples reinforced the water hyacinth fibers had a marked improvement after treatment of the water hyacinth fibers. Further research should be carried out with various adhesives and more environmental friendly.

\section{NOMENCLATURE}

ASTM American Society for Testing and Materials

SEM Scanning Electron Microscopy

UPE Unsaturated Polyester

UWH Untreated Water Hyacinth

TWH Treated Water Hyacinth

\section{REFERENCES}

1. Urantinon Apichote, The study on physical characteristics of water hyacinth fibers by scanning electron microscopy, $J$ Ind Technol. 2019; 7(2): 51-60p.

2. Nguyen Thuc Boi Huyen, Research on effective solution of water hyacinth in mekong delta, J Econ Ind. 2014; 4: 88-92p.

3. Tumolva TP, Ortenero J, Kubouchi M. Characterization and Treatment of water hyacinth fibers for NFRP composites, The $19^{\text {th }}$ International Conference on Composite Materials, 2013; 28; 1-11p.

4. Ortenero JR, Tumolva TP, Kubouchi M. Water hyacinth fiber-reinforced green composites, Proceeding of the $7^{\text {th }}$ International Workshop on Green Composites (IWGC-7), Hamamatsu, Japan, 2012.

5. Bali G, Meng X, Deneff JI, Sun Q, Ragauskas AJ. The effect of alkaline pretreatment methods on cellulose structure and accessibility, Chem Sus Chem. 2014; 8(2): 275-279p.

6. Kalia S, Kaith BS, Kaur I. Pretreatments of natural fibers and their application as reinforcing material in polymer composites - A review, Polym Eng Sci. 2009; 49: 1253-1272p.

7. Punyamurthy R, Dhanalakshmi S, Venkateshappa SC, Bennehalli B. Effect of alkali treatment on water absorption of single cellulosic Abaca fibre, BioResources. 2012; 7(3): 3515-3524p.

8. Abdul Motaleb KZM, Islam MS, Hoque MB. Improvement of physicomechanical properties of pineapple leaf fiber reinforced composite, Int J Biomater. 2018; 2018: 1$7 p$.

9. Rao PD, Naidu AL, Raju Bahubalenruni MVA. Mechanical properties of banana fiber reinforced composites and manufacturing techniques: A review, Int $J$ Res Dev Tech. 2017; 8(5): 2349-3585p.

10. Maisuriya V, Jain PS, Jariwala H, Badagha DG. Analysis of unidirectional aligned banana and glass fiber reinforced polyester composite for tensile and flexural strength, J Polym Compos. 2020; 8(2): 49-61p.

11. Udhayasankar R, Karthikeyan B. A review on coconut shell reinforced composites, Int J ChemTech Res. 2015; 8(11): 624$637 \mathrm{p}$. 
12. Singh N, Pandey VK, Kale SA, An organized study of jute fiber composites and selection of better materials using a simplified approach, J Polym Compos. 2020; 8(2): 1-8p.

13. Yogish CK, Pradeep S, Raghavendra RR, Sunil KG. Effect of silicon carbide on the mechanical properties of the rice husk, corn cob polymer matrix composites, $J$ Polym Compos. 2020; 8(1): 39-45p.

14. Do Quang Minh, Nguyen Vu Uyen Nhi, Nguyen Hoc Thang. Development of refractory synthesized from waste ceramic fiber and chamotte. J Polym Compos. 2020; 8(2): 101-109p.

15. Nguyen Hoc Thang. Novel porous refractory synthesized from diatomaceous earth and rice husk ash. $J$ Polym Compos. 2020; 8(2): 128-137p.

16. Abral H, Kadriadi D, Rodianus A, Mastariyanto P, Ilhamdi, Arief S, Sapuan SM, Ishak MR. Mechanical properties of water hyacinth fibers - polyester before and after immersion in water, Mater Des. 2014; 58: 125-129p.

\section{Cite this Article}

Nguyen Thuc Boi Huyen, Nguyen Hoc Thang. Eco-friendly Materials of Polymer Composites Based on Water Hyacinth Fibers/Roving. Journal of Polymer \& Composites. 2020; 8(3): 62-69p. 